\title{
AMPK and SIRT1 activation contribute to inhibition of neuroinflammation by thymoquinone in BV2 microglia
}

\author{
Ravikanth Velagapudi $^{1,2}$ - Abdelmeneim El-Bakoush ${ }^{1}$ - Izabela Lepiarz ${ }^{1}$. \\ Folashade Ogunrinade ${ }^{1} \cdot$ Olumayokun A. Olajide $^{1}$
}

Received: 26 November 2016/ Accepted: 5 May 2017/Published online: 27 May 2017

(C) The Author(s) 2017. This article is an open access publication

\begin{abstract}
Thymoquinone is a known inhibitor of neuroinflammation. However, the mechanism(s) involved in its action remain largely unknown. In this study, we investigated the roles of cellular reactive oxygen species (ROS), $5^{\prime}$ AMP-activated protein kinase (AMPK) and sirtuin 1 (SIRT1) in the anti-neuroinflammatory activity of thymoquinone. We investigated effects of the compound on ROS generation in LPS-activated microglia using the fluorescent $2^{\prime}, 7^{\prime}$-dichlorofluorescin diacetate (DCFDA)-cellular ROS detection. Immunoblotting was used to detect protein levels of $\mathrm{p} 40^{\text {phox }}, \mathrm{gp} 91^{\text {phox }}$, AMPK, LKB1 and SIRT1. Additionally, ELISA and immunofluorescence were used to detect nuclear accumulation of SIRT1. NAD ${ }^{+} / \mathrm{NADH}$ assay was also performed. The roles of AMPK and SIRT1 in anti-inflammatory activity of thymoquinone were investigated using RNAi and pharmacological inhibition. Our results show that thymoquinone reduced cellular ROS generation, possibly through inhibition of $\mathrm{p} 40^{\text {phox }}$ and gp91 $1^{\text {phox }}$ protein. Treatment of BV2 microglia with thymoquinone also resulted in elevation in the levels of LKB1 and phospho-AMPK proteins. We further observed that thymoquinone reduced cytoplasmic levels and increased nuclear accumulation of SIRT1 protein and increased levels of $\mathrm{NAD}^{+}$. Results also show that the anti-inflammatory activity of thymoquinone was abolished when the
\end{abstract}

Olumayokun A. Olajide

o.a.olajide@hud.ac.uk

1 Department of Pharmacy, School of Applied Sciences, University of Huddersfield, Queensgate, Huddersfield, West Yorkshire HD1 3DH, UK

2 Present Address: Neurobiology Laboratory, National Institute of Environmental Health Sciences, National Institutes of Health, Research Triangle Park, NC, USA expressions of AMPK and SIRT1 were suppressed by RNAi or pharmacological antagonists. Pharmacological antagonism of AMPK reversed thymoquinone-induced increase in SIRT1. Taken together, we propose that thymoquinone inhibits cellular ROS generation in LPS-activated BV2 microglia. It is also suggested that activation of both AMPK and $\mathrm{NAD}^{+} /$SIRT1 may contribute to the antiinflammatory, but not antioxidant activity of the compound in BV2 microglia.

Keywords Thymoquinone - AMPK $\alpha \cdot$ ROS - SIRT1 . Neuroinflammation

\section{Background}

Accumulating evidence suggests that there is a strong link between oxidative stress and inflammation. An unbalanced redox state is known to contribute to the pathogenesis of inflammatory conditions, including ageing [1]. Furthermore, it is now widely accepted that inflammation triggers the generation of elevated levels of cellular reactive oxygen species that cause cellular oxidative damage [2]. On the other hand, inflammatory cells respond to oxidative stress by releasing various $\mathrm{NF}-\kappa \mathrm{B}$-mediated pro-inflammatory mediators [3]. Oxidative stress has also been linked to neuroinflammation. Accumulating evidence indicates that reactive oxygen species (ROS) produced by the microglia have a significant impact on adjacent neurons, as well as modulating microglial activity [4]. It has been shown that the activated microglia M1 phenotype is associated with elevated levels of NADPH oxidase (NOX)-dependent ROS generation [5]. Consequently, oxidative stress is now recognised as an important contributor to 
neuroinflammation, and its resultant neuronal damage in neurodegenerative disorders.

Adenosine monophosphate-activated protein kinase (AMPK) is a well-known sensor of energy balance by responding to ATP-depleting processes such as cellular stress [6]. Recent evidence now suggests that AMPK regulates inflammatory responses [7]. AMPK has been shown to be critical for inducing macrophages from a pro-inflammatory to anti-inflammatory phenotype during inflammation [8]. AMPK activation therefore appears to be a potential strategy for inhibiting inflammation.

Sirtuin 1 (SIRT1) is a member of the sirtuin family which has been linked to cellular processes, including neuroinflammation. SIRT1 is responsible for deacetylation of transcription factors, including p65 subunit of NF- $\kappa B$ during inflammation [9-14]. Due to its negative modulatory effect on inflammation, activation of SIRT1 appears to be critical to achieving anti-inflammatory activity.

Thymoquinone (Fig. 1) is the main constituent of the oil obtained from the seeds of Nigella sativa (black cumin seed oil), and has been widely reported to produce antiinflammatory activity [15-18]. This compound has been shown to inhibit neuroinflammation in mix glial cells [19] and BV2 microglia [20-22].

In this study, we report that thymoquinone activation of both AMPK and SIRT contribute to inhibition of neuroinflammation and cellular ROS by thymoquinone in BV2 microglia.

\section{Methods}

\section{Cell culture}

BV2 mouse microglia cell line ICLC ATL03001 (Interlab Cell Line Collection, Banca Bilogica e Cell Factory, Italy) was maintained in RPMI1640 medium with $10 \%$ fetal bovine serum (FBS) (Sigma), $2 \mathrm{mM}$ L-glutamine (Sigma), $100 \mathrm{U} / \mathrm{mL}$ penicillin and $100 \mathrm{mg} / \mathrm{mL}$ streptomycin (Sigma) in a $5 \% \mathrm{CO}_{2}$ incubator.

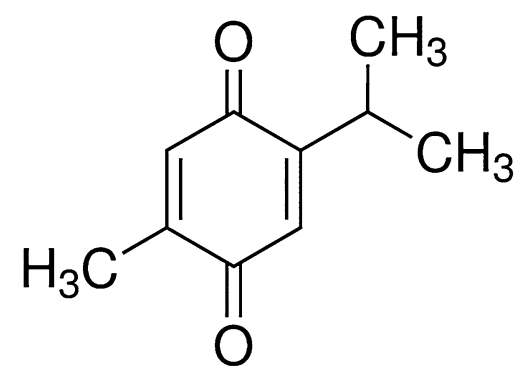

Fig. 1 Structure of thymoquinone

\section{Intracellular cellular ROS production}

Determination of intracellular reactive oxygen species (ROS) levels in BV2 microglia was performed using the fluorescent $2^{\prime}, 7^{\prime}$-dichlorofluorescin diacetate DCFDA-cellular reactive oxygen species detection assay kit (Abcam). Briefly, BV2 microglia were incubated with $10 \mu \mathrm{M}$ DCFDA for $30 \mathrm{~min}$ at $37^{\circ} \mathrm{C}$. After removal of excess DCFDA, the cells were washed and then exposed to LPS $(100 \mathrm{ng} / \mathrm{mL})$ for $4 \mathrm{~h}$ at $37{ }^{\circ} \mathrm{C}$ in the presence or absence of thymoquinone $(2.5-10 \mu \mathrm{M})$. Intracellular production of ROS was measured by the fluorescence detection of dichlorofluorescein (DCF) as the oxidised product of DCFH on a microplate reader with an excitation wavelength of $485 \mathrm{~nm}$ and emission wavelength of $535 \mathrm{~nm}$.

\section{Immunoblotting}

For Western blotting, 20-40 $\mu \mathrm{g}$ of total protein from cell samples was subjected to SDS-PAGE under reducing conditions. Proteins were then transferred onto polyvinylidene fluoride (PVDF) membranes (Millipore). The membranes were blocked for $1 \mathrm{~h}$ at room temperature and then incubated overnight at $4{ }^{\circ} \mathrm{C}$ with primary antibodies. Primary antibodies used were rabbit anti-SIRT1 (Santa Cruz), rabbit anti-phospho-AMPK $\alpha$ (Santa Cruz), rabbit anti-total AMPK $\alpha$ (Santa Cruz), rabbit anti-LKB1 (Santa Cruz) and rabbit anti-actin (Sigma). Primary antibodies were diluted in Tris-buffered saline (TBS), containing $0.1 \%$ Tween 20 (TBS-T) and 1 or 5\% BSA. Membranes were incubated with the primary antibody overnight at $4{ }^{\circ} \mathrm{C}$. After extensive washing (three times for 15 min each in TBS-T), proteins were detected by incubation with Alexa Fluor 680 goat anti-rabbit secondary antibody (1:10,000; Life Technologies) at room temperature for $1 \mathrm{~h}$. Detection was done using a LICOR Odyssey Imager. All Western blot experiments were carried out at least three times.

\section{SIRT1 ELISA}

BV2 microglia were seeded in a 6-well plate for $48 \mathrm{~h}$. Thereafter, cells were treated with $2.5-10 \mu \mathrm{M}$ thymoquinone for $24 \mathrm{~h}$. Following treatment, nuclear extracts were prepared and analysed for levels or SIRT1 using a mouse SIRT1 ELISA kit (Abcam), according to the manufacturer's instructions.

\section{$\mathrm{NAD}^{+} / \mathrm{NADH}$ quantification}

BV2 microglia were seeded in a 6-well plate and treated with thymoquinone $(2.5-10 \mu \mathrm{M})$ for $24 \mathrm{~h}$. Cell lysates were collected with $400 \mu \mathrm{L}$ of NADH/NAD extraction buffer 
(Abcam). Quantification of NADH and NAD, and their ratio was carried out with a colorimetric NAD/NADH assay kit (Abcam), according to the manufacturer's instructions.

\section{RNA interference}

Small interfering RNA (siRNA) targeted at mouse AMPK (Santa Cruz Biotechnology) was used to knockout AMPK. $\mathrm{BV} 2$ cells were cultured and incubated at $37{ }^{\circ} \mathrm{C}$ in a $5 \%$ $\mathrm{CO}_{2}$ incubator until 70-80\% confluent. Cells were then seeded out in a 6-well plate at a density of $1 \times 10^{6}$ cells/ well. AMPK siRNA duplex $(10 \mu \mathrm{M})$ were diluted in OptiMEM $^{\circledR}$ medium (Thermo Scientific). Lipofectamine ${ }^{\circledR}$ RNAiMAX transfection reagent (Thermo Scientific) was also diluted in Opti-MEM ${ }^{\circledR}$ medium. Thereafter, the diluted siRNA was added to diluted lipofectamine ${ }^{\circledR}$ RNAiMAX reagent (1:1 ratio). The siRNA-lipid complex was then incubated at room temperature for $5 \mathrm{~min}$. The complex was thereafter added to cells and incubated for a further $24 \mathrm{~h}$. Following transfection, media was changed in transfected cells to complete media and incubated for a further $18 \mathrm{~h}$. Effects of thymoquinone $(10 \mu \mathrm{M})$ on NO, PGE2, TNFa, IL$1 \beta$, IL-6 and ROS production in LPS-stimulated control siRNA and AMPK siRNA-transfected BV2 cells were then determined. Similar procedures were used to transfect BV2 cells with mouse SIRT1 siRNA (Santa Cruz Biotechnology), prior to experiments to evaluate effects of thymoquinone $(10 \mu \mathrm{M})$ on $\mathrm{NO}, \mathrm{PGE}_{2}, \mathrm{TNF} \alpha$, IL-1 $\beta$, IL-6 and ROS production in LPS-stimulated BV2 cells.

\section{Evaluation of the effects of AMPK inhibitor on the anti-inflammatory and antioxidant activities of thymoquinone in LPS-activated BV2 microglia}

We further investigated whether pharmacological inhibition of AMPK with compound C (Sigma) would affect anti-inflammatory and antioxidant activities of thymoquinone in LPS-activated microglia. Cultured BV2 microglia were treated with compound $\mathrm{C}(10 \mu \mathrm{M})$. One hour later, cells were treated with thymoquinone $(10 \mu \mathrm{M})$ prior to stimulation with LPS $(100 \mathrm{ng} / \mathrm{mL})$ for a further $24 \mathrm{~h}$. Culture supernatants were analysed for levels of TNF $\alpha$, IL-6, IL1 $\beta$, NO, PGE 2 . Generation of cellular ROS was determined using the DCFDA method.

\section{Evaluation of the effects of SIRT1 inhibitor on the anti-inflammatory and antioxidant activities of thymoquinone in LPS-activated BV2 microglia}

Pharmacological inhibition of SIRT1 using EX527 (Tocris) was used to determine whether SIRT1 is required for the antiinflammatory and antioxidant actions of thymoquinone in the microglia. BV2 cells were treated with EX527 $(1 \mu \mathrm{M})$ followed by thymoquinone $(10 \mu \mathrm{M})$ prior to stimulation with LPS (100 ng/mL) for $24 \mathrm{~h}$. Culture supernatants were analysed for levels of TNF $\alpha$ (Biolegend, UK), IL-6 (Biolegend, UK), IL1 $\beta$ (Biolegend, UK), NO (Promega, UK), $\mathrm{PGE}_{2}$ (Arbor Assays, USA). Generation of cellular ROS was determined using the DCFDA method (Abcam, UK).

\section{Determination of SIRT-1 activation by thymoquinone in the presence of AMPK inhibitor}

We were also interested in the role played by AMPK in the activation of SIRT1 by thymoquinone. Cultured BV2 microglia were therefore treated with thymoquinone $(10 \mu \mathrm{M})$ in the presence and absence of the AMPK inhibitor, compound $(10 \mu \mathrm{M})$. Thereafter, protein levels of nuclear SIRT1 were determined using immunoblotting and ELISA. Also, levels of $\mathrm{NAD}^{+} / \mathrm{NADH}$ were quantified in cell extracts.

\section{Statistical analysis}

Values of all experiments were represented as a mean \pm SEM of at least 3 experiments. Values were compared using one-way ANOVA followed by a post hoc Student Newman-Keuls test.

\section{Results}

Generation of NADPH oxidase (NOX)-dependent cellular reactive oxygen species (ROS) in LPSactivated BV2 microglia was inhibited by thymoquinone

Generation of intracellular ROS is a major component of LPS-induced neuroinflammation. We therefore investigated the effect of thymoquinone on LPS-induced generation of ROS in BV2 microglia. Following a 24-h stimulation of microglia with LPS, there was a marked generation of intracellular ROS (Fig. 2a). On treating cells with thymoquinone $(2.5,5$ and $10 \mu \mathrm{M})$, we observed a significant $(p<0.001)$ and concentration-dependent attenuation of intracellular ROS generation, suggesting that thymoquinone is antioxidant in LPS-activated microglia.

Following our observation that thymoquinone produced antioxidant activity against LPS-induced ROS generation, we were interested in establishing whether this effect was mediated by targeting the NADPH oxidase (NOX) enzymes. To investigate this, we carried out western blotting for the cytoplasmic p-p40 ${ }^{\text {phox }}$ and membrane-bound gp91 $1^{\text {phox }}$ NOXs in BV2 microglia stimulated with LPS in the presence of thymoquinone. Stimulation of BV2 cells for $24 \mathrm{~h}$ resulted in elevation of both $\mathrm{p}-\mathrm{p} 40^{\text {phox }}$ and 


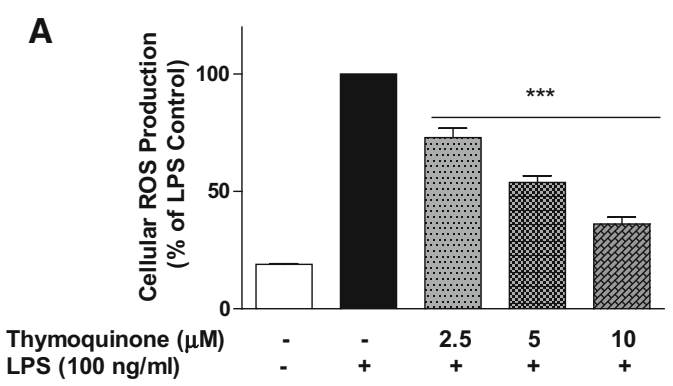

B

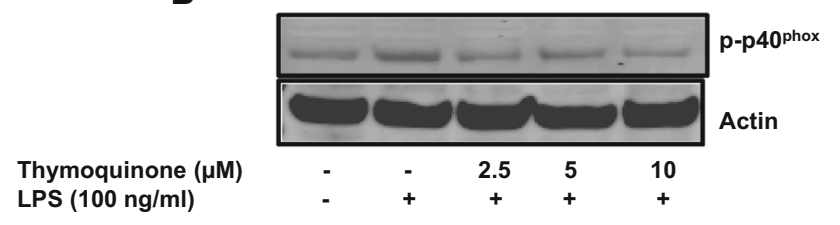

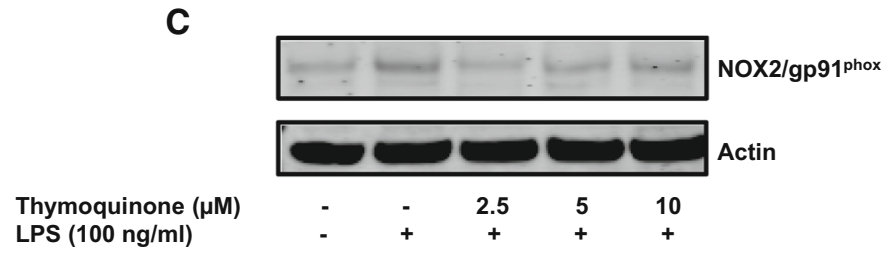

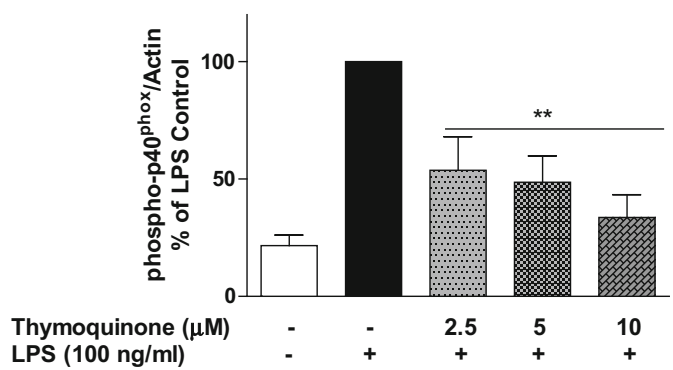

Fig. 2 Thymoquinone inhibits NADPH oxidase-mediated ROS generation in LPS-activated BV2 microglia. a BV2 cells were treated with vehicle or thymoquinone $(2.5-10 \mu \mathrm{M})$ for $30 \mathrm{~min}$ prior to LPS stimulation for $24 \mathrm{~h}$. ROS generation was measured in live cells by the fluorescence detection of dichlorofluorescein. (Mean \pm SEM; $* * * p<0.001$; one-way ANOVA with post hoc Student NewmanKeuls test). b BV2 cells were treated with vehicle or thymoquinone $(2.5-10 \mu \mathrm{M})$ for $30 \mathrm{~min}$ prior to LPS stimulation for $24 \mathrm{~h}$. Cell lysates were analysed using immunoblotting for $\mathrm{p}-\mathrm{p} 40^{\mathrm{phox}}$ and actin.

gp91 ${ }^{\text {phox }}$ proteins (Fig. 2b, c). Treatment of cells with thymoquinone $(2.5-10 \mu \mathrm{M})$ prior to LPS, resulted in significant reduction of both NADPH oxidases.

\section{Thymoquinone activates LKB-1/AMPK $\alpha$ in BV2 microglia}

It has been suggested that AMPK contributes to the antioxidant mechanisms by stimulating Nrf2 signalling in immune cells such as RAW 264.7 macrophages [23]. Zimmermann et al. have also shown that activation of AMPK enhances Nrf2/HO1 signalling. We therefore aimed to evaluate the effects of thymoquinone on AMPK and its upstream kinase LKB-1 in BV2 microglia [24]. Preliminary immunoblotting to determine time-point of AMPK activation by thymoquinone $(10 \mu \mathrm{M})$ shows that maximum activation was detected at $12 \mathrm{~h}$ (Fig. 3a). Western blotting experiments show that treatment with thymoquinone

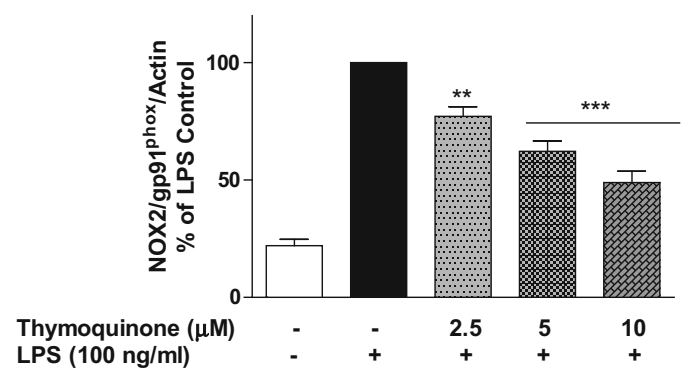

Representative blots and densitometric analyses of three independent experiments are shown (Mean $\pm \mathrm{SEM} ; * * p<0.01$; one-way ANOVA with post hoc Student Newman-Keuls test). c BV2 cells were treated with vehicle or thymoquinone $(2.5-10 \mu \mathrm{M})$ for $30 \mathrm{~min}$ prior to LPS stimulation for $24 \mathrm{~h}$. Membrane extracts were analysed using immunoblotting for gp $91^{\text {phox }}$ and actin. Representative blots and densitometric analyses of three independent experiments are shown (Mean $\pm \mathrm{SEM}$; **p $<0.01, * * * p<0.001$; one-way with ANOVA post hoc Student Newman-Keuls test)

$(2.5 \mu \mathrm{M})$ for $12 \mathrm{~h}$ produced a slight increase in the levels of phosphorylated AMPK $\alpha$. On increasing the concentration of thymoquinone to 5 and $10 \mu \mathrm{M}$, there was $\sim 1.7$ and $\sim 2.3$-fold elevation in the levels of the phosphorylated AMPK $\alpha$, respectively (Fig. 3b). LKB-1 is a kinase that is known to directly phosphorylate and activate AMPK. Therefore, we evaluated the effect of thymoquinone treatment on LKB-1 protein in BV2 microglia. Our experiments show that incubating BV2 microglia with thymoquinone (5 and $10 \mu \mathrm{M}$ ) for $12 \mathrm{~h}$ resulted in an increase in LKB-1 protein in a similar fashion as AMPK $\alpha$ (Fig. 3c).

\section{AMPK siRNA transfection and compound C treatment reversed anti-inflammatory effect of thymoquinone in LPS-activated BV2 microglia}

Based on our observation that thymoquinone could activate AMPK $\alpha$, we became interested in elucidating the role of 
A

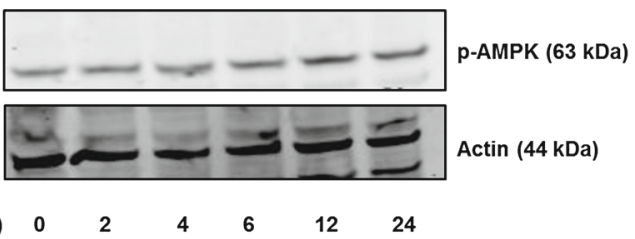

Thymoquinone $(10 \mu \mathrm{M} /$ Time (h) 0

$\begin{array}{llll}4 & 12 & 24\end{array}$

B
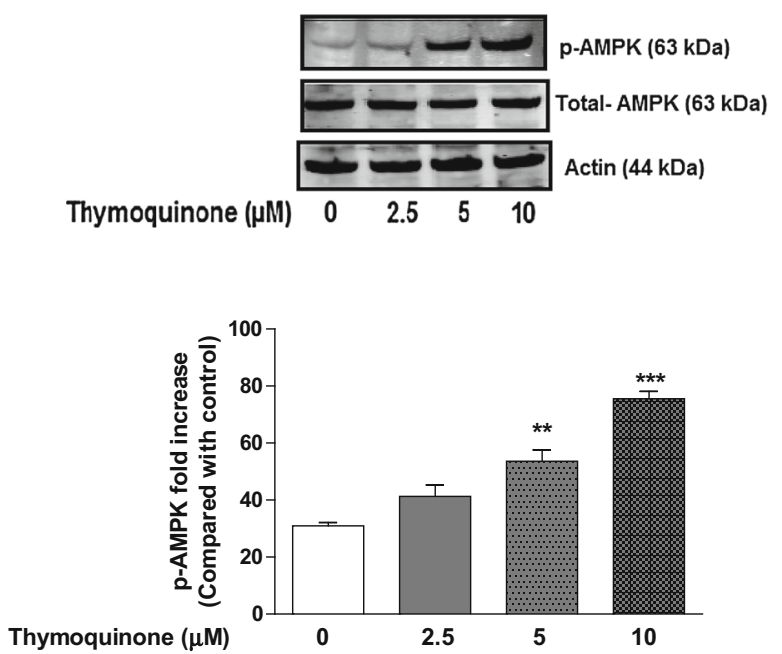

Fig. 3 Thymoquinone activates $\operatorname{AMPK} \alpha(\mathbf{a}, \mathbf{b})$ and its upstream kinase LKB1 (c). BV2 microglia were treated with thymoquinone $(2.5-10 \mu \mathrm{M})$ for $12 \mathrm{~h}$. Cell lysates were analysed using immunoblotting for phospho-AMPK $\alpha$ and total AMPK $\alpha$ (a), LKB1 and actin (b).

this activation on the anti-inflammatory activity of the compound in BV2 microglia. AMPK $\alpha$ siRNA-transfected cells were treated with $10 \mu \mathrm{M}$ thymoquinone, followed by LPS $(10 \mu \mathrm{M})$ stimulation for $24 \mathrm{~h}$. Analyses of culture supernatants revealed that thymoquinone $(10 \mu \mathrm{M})$ prevented the release of pro-inflammatory mediators from control siRNA-transfected BV2 microglia (Fig. 4a-e). Similarly, thymoquinone suppressed binding of activated NF- $\kappa B$ to its consensus binding sites on the DNA (Fig. 4f). In AMPK $\alpha$ siRNA-transfected cells however, the ability of thymoquinone to inhibit NF- $\mathrm{KB}$-mediated neuroinflammation was significantly diminished $(p<0.05)$, in comparison with control siRNA-transfected cells (Fig. 4a-f). Similarly, reduction of LPS-induced ROS generation in BV2 cells was significantly reversed when cells were transfected with AMPK siRNA (Fig. 4g). Western blotting analyses show that AMPK protein was efficiently reduced in AMPK siRNA-transfected cells (Fig. 4h).

To confirm our observations, we treated BV2 cells with a known inhibitor of AMPK, (compound C) prior to thymoquinone treatment and subsequent stimulation with LPS for $24 \mathrm{~h}$. Interestingly, inhibition of inflammatory mediator (TNF $\alpha$, IL-6, IL-1 $\beta, \mathrm{NO}, \mathrm{PGE}_{2}$ ) release as well as NF- $\kappa \mathrm{B}$ DNA binding by thymoquinone $(10 \mu \mathrm{M})$ were
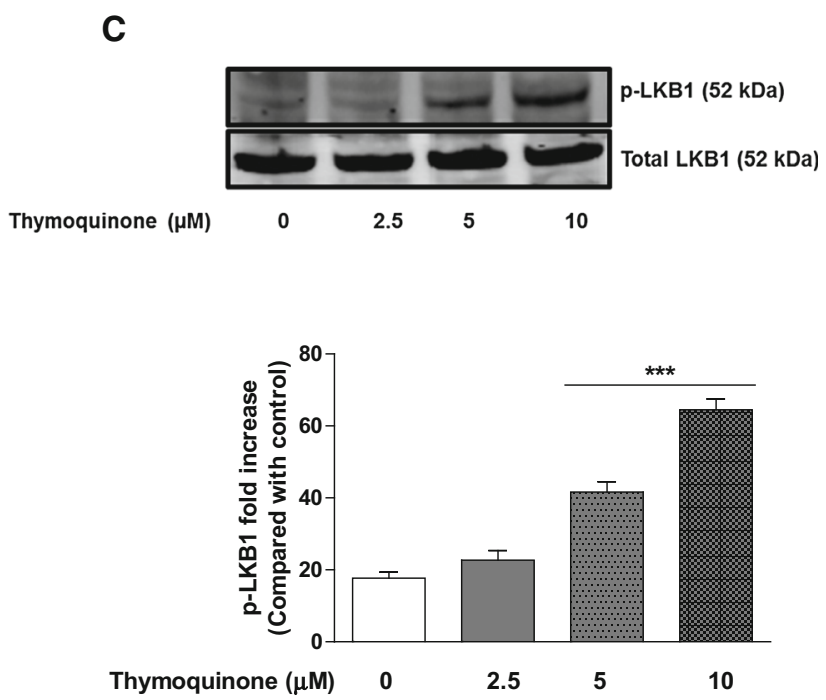

Representative blots and densitometric analyses of three independent experiments are shown (Mean $\pm \mathrm{SEM} ; * * p<0.01$, *** $p<0.001$; one-way ANOVA with ANOVA post hoc Student Newman-Keuls test)

significantly $(p<0.05)$ reversed in the presence of compound $\mathrm{C}(10 \mu \mathrm{M})$ (Fig. 5a-f). In Fig. 5g, results show that the effect of thymoquinone on LPS-induced ROS generation in BV2 cells was lost in the presence of compound $\mathrm{C}$.

\section{Thymoquinone induces $\mathrm{NAD}^{+}$-dependent nuclear localisation of SIRT1 in BV2 microglia}

It is now established that SIRT1 deacetylates p65, resulting in the inhibition of the transcriptional ability of NF- $\kappa \mathrm{B}$ [11]. Based on our earlier observation that thymoquinone attenuated LPS-induced p65 acetylation in BV2 microglia, we wanted to find out whether the compound could also be activating SIRT1. Immunoblotting results in Fig. 6a shows that treating $\mathrm{BV} 2$ microglia with thymoquinone $(2.5-10 \mu \mathrm{M})$ for $24 \mathrm{~h}$ resulted in significant $(p<0.001)$ accumulation of SIRT1 protein in the nucleus. This was shown to correspond to a concentration-dependent reduction in levels of this sirtuin from the cytoplasm (Fig. 6b). Immunofluorescence data (Fig. 6c) show an increase in SIRT1 immunostaining in BV2 microglia treated with thymoquinone (5 and $10 \mu \mathrm{M}$ ). Similar results were obtained in a mouse SIRT1 ELISA, which shows $\sim 1$, 

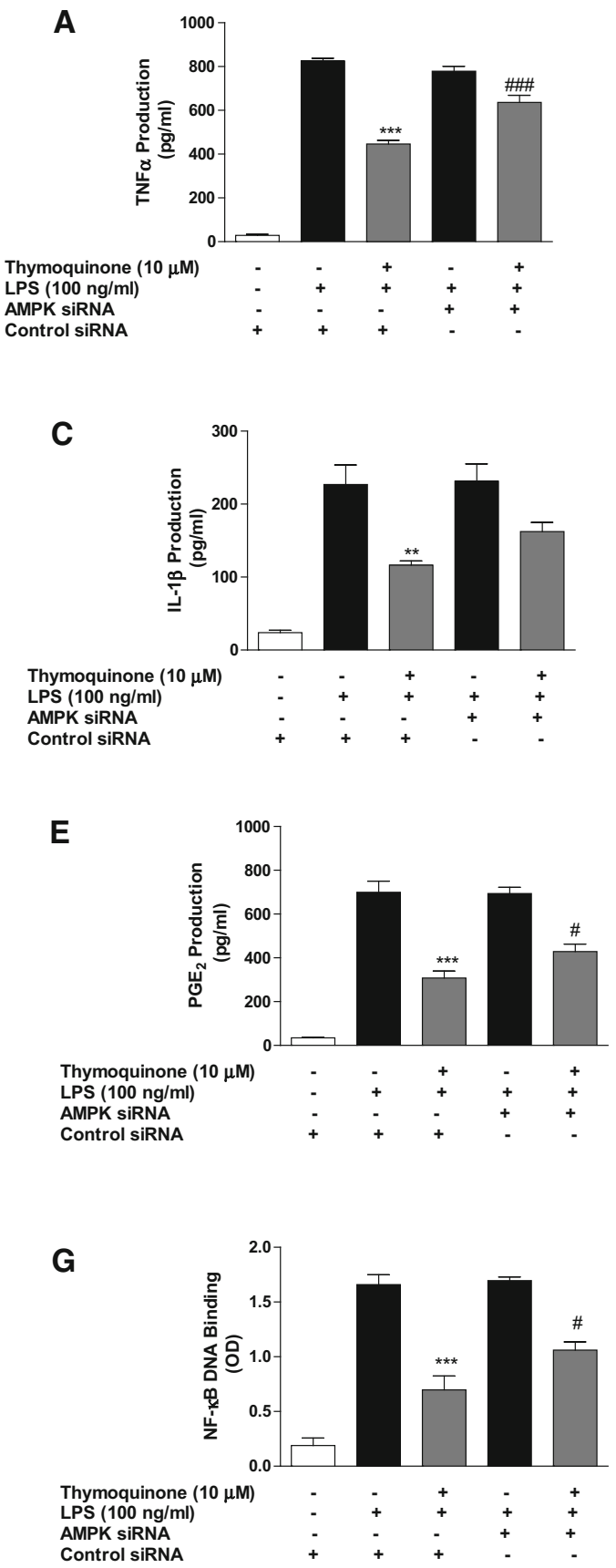
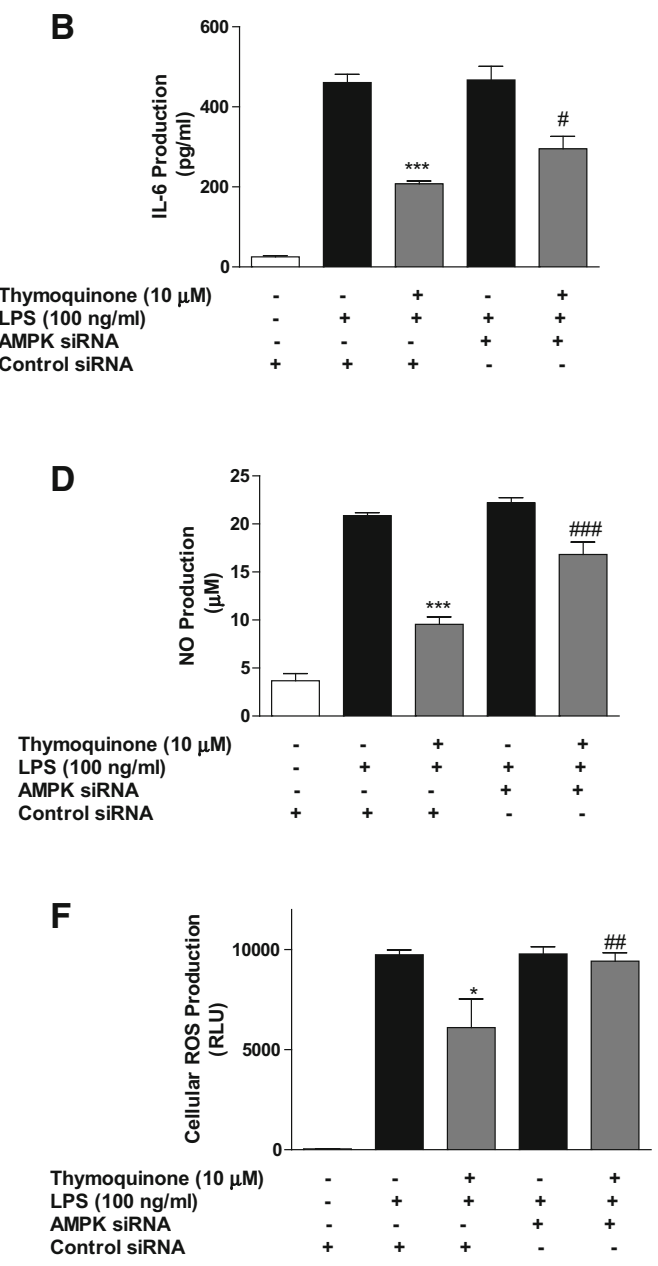

H

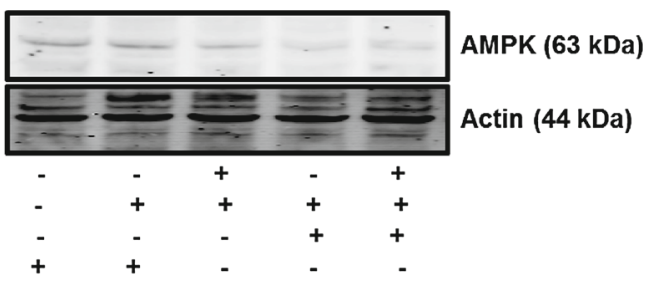

Fig. 4 Inhibition of neuroinflammation by thymoquinone is dependent on AMPK $\alpha$. Control siRNA- and AMPK $\alpha$ siRNA-transfected BV2 cells were pre-treated with thymoquinone $(10 \mu \mathrm{M})$ prior to stimulation with LPS $(100 \mathrm{ng} / \mathrm{ml})$ for $24 \mathrm{~h}$. Cells were analysed for TNF $\propto$ (a), IL-6 (b), IL-1 $\beta$ (c), nitrite (d) $\mathrm{PGE}_{2}$ (e) and ROS (f). In g nuclear extracts from cells were added to 96-well plates to which an oligonucleotide containing the NF- $\mathrm{KB}$ consensus site $\left(5^{\prime}\right.$ GGGACTTTCC $-3^{\prime}$ ) has been immobilised, followed by addition of $\mathrm{NF}-\kappa \mathrm{B}$ and HRP-conjugated antibodies. Absorbance was read in a

$\sim 1.3$ and $\sim 1.5$-fold increase in SIRT1 in cells treated with $2.5,5$ and $10 \mu \mathrm{M}$ thymoquinone, respectively (Fig. 6d). microplate reader. Western blot experiments on cell extracts to determine knockout efficiency (h). (Mean $\pm \mathrm{SEM} ; * * p<0.01$, $* * * p<0.001$ thymoquinone + LPS treatment compared with LPS

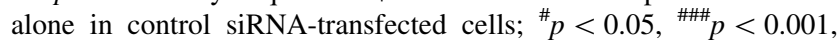
thymoquinone + LPS treatment in AMPK siRNA-transfected cells compared with thymoquinone + LPS treatment in control siRNAtransfected cells; one-way ANOVA with ANOVA post hoc Student Newman-Keuls test)

We also investigated the effect of thymoquinone on $\mathrm{NAD}^{+} / \mathrm{NADH}$ ratio in $\mathrm{BV} 2$ microglia, and showed that treatment with the compound resulted in statistically 

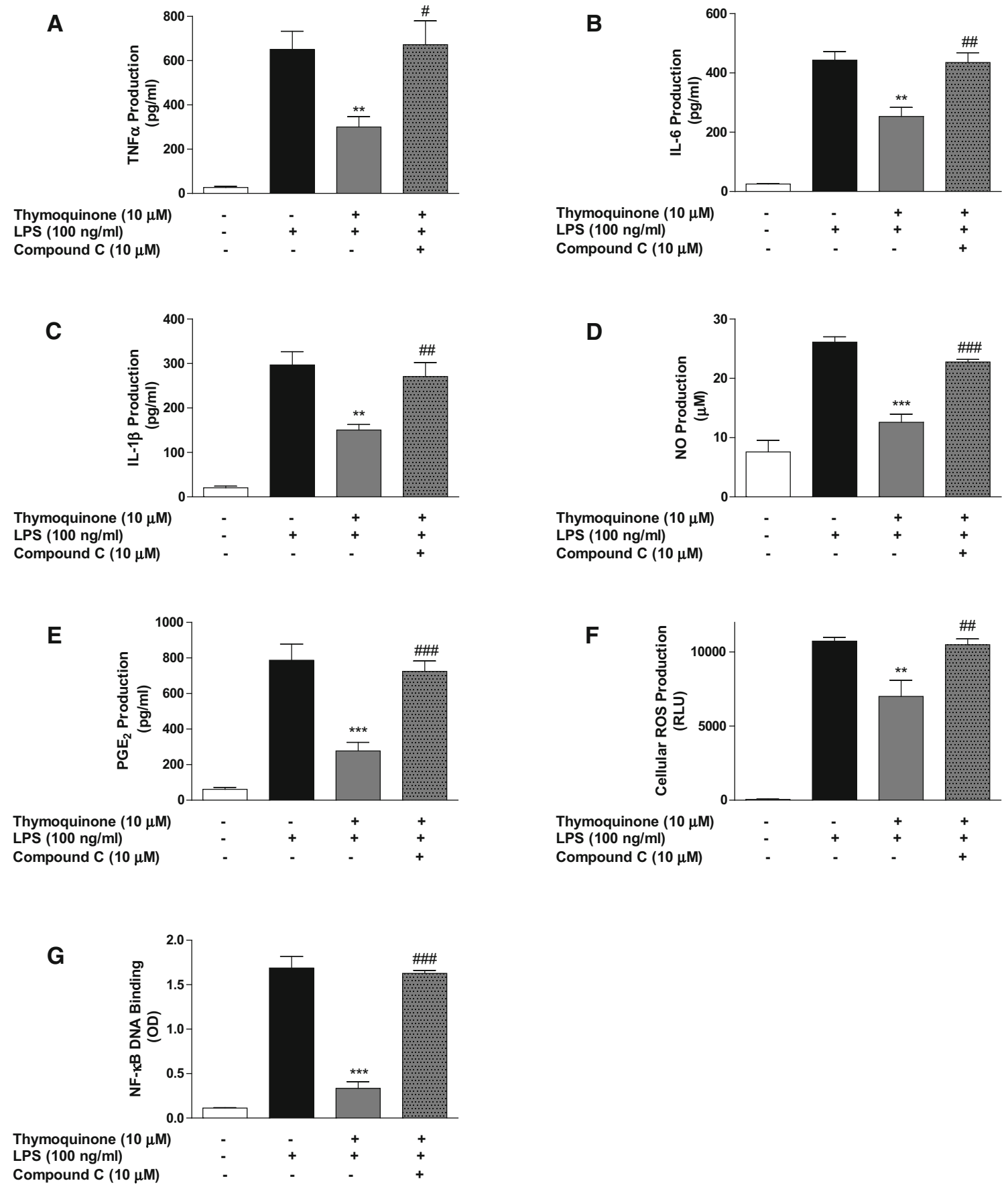

Fig. 5 Inhibition of neuroinflammation by thymoquinone was abolished in the presence of compound C. BV2 cells were treated with compound $\mathrm{C}(10 \mu \mathrm{M})$, followed by thymoquinone $(10 \mu \mathrm{M})$ and LPS $(100 \mathrm{ng} / \mathrm{ml})$ for $24 \mathrm{~h}$. Cells were analysed for TNFa (a), IL-6 (b), IL$1 \beta(\mathbf{c})$, nitrite (d), $\mathrm{PGE}_{2}(\mathbf{e})$ and $\mathrm{ROS}(\mathbf{f})$. In $\mathbf{g}$ nuclear extracts from cells were added to 96-well plates to which an oligonucleotide containing the NF- $\kappa \mathrm{B}$ consensus site (5'-GGGACTTTCC-3') has

been immobilised, followed by addition of NF- $\kappa \mathrm{B}$ and HRPconjugated antibodies. Absorbance was read in a microplate reader. (Mean \pm SEM; $* * p<0.01, \quad * * * p<0.001$ compared with LPS stimulation; $\quad \# p<0.05, \quad \# p<0.01, \quad \# \#<0.001$, compound $\mathrm{C}+$ thymoquinone + LPS treatment compared with thymoquinone + LPS treatment; one-way ANOVA with ANOVA post hoc Student Newman-Keuls test) 

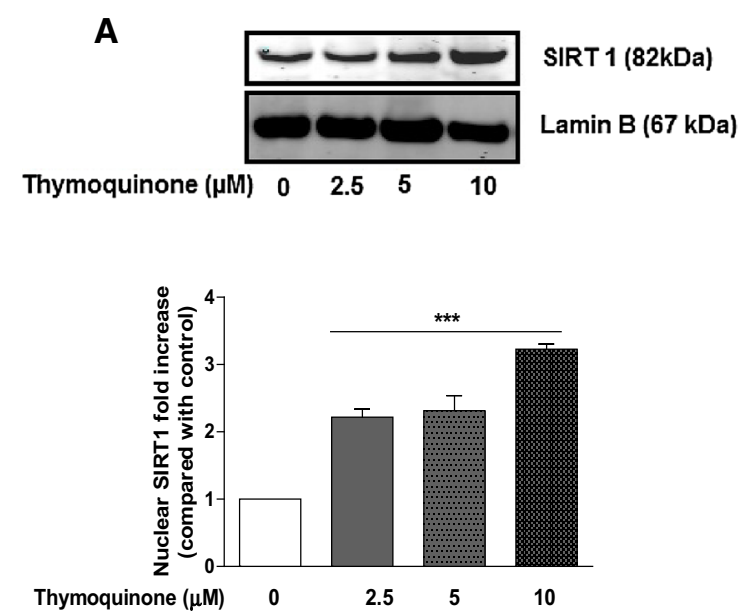

C
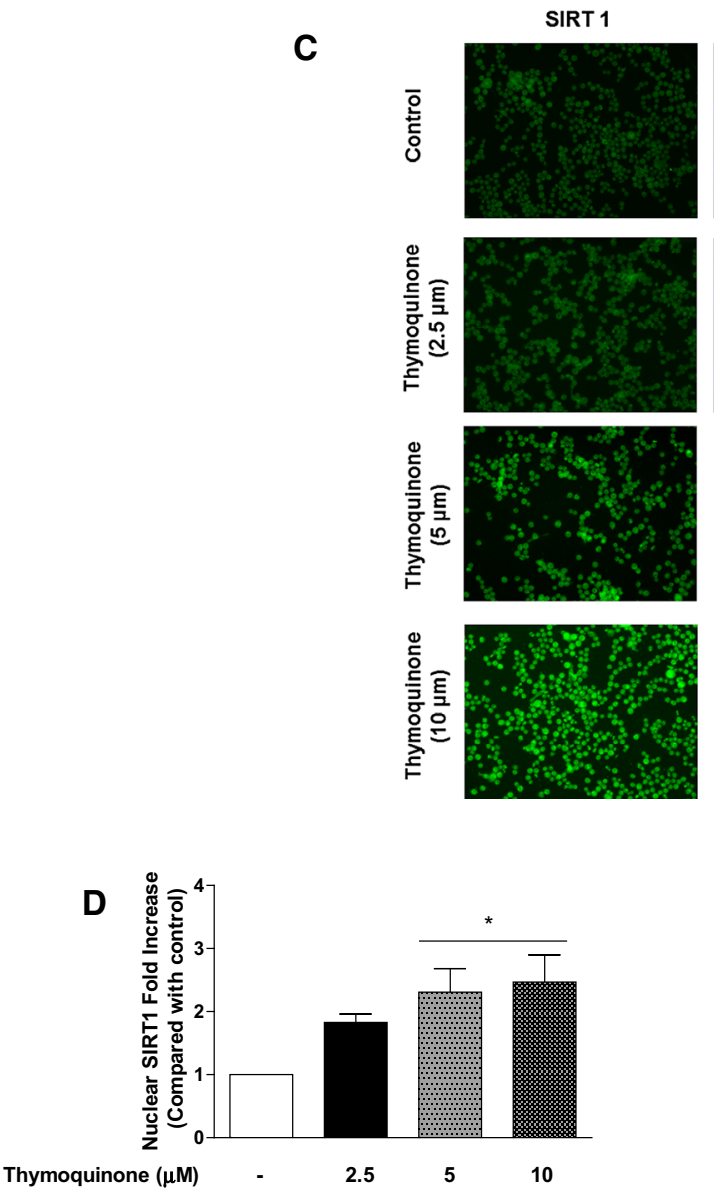

Fig. 6 Thymoquinone activates SIRT1 in BV2 microglia. a BV2 cells were treated with vehicle or thymoquinone $(2.5-10 \mu \mathrm{M})$ for $12 \mathrm{~h}$. Nuclear extracts were analysed using immunoblotting for SIRT1 and lamin B. Representative blots and densitometric analyses of three independent experiments are shown (Mean \pm SEM; $* * * p<0.001$; one-way ANOVA). b BV2 cells were treated with vehicle or thymoquinone $(2.5-10 \mu \mathrm{M})$ for $12 \mathrm{~h}$. Cytoplasmic extracts were analysed using immunoblotting for SIRT-1 and actin. Representative blots and densitometric analyses of three independent experiments are shown (Mean $\pm \operatorname{SEM} ; * * p<0.01$, ***p $<0.001$;
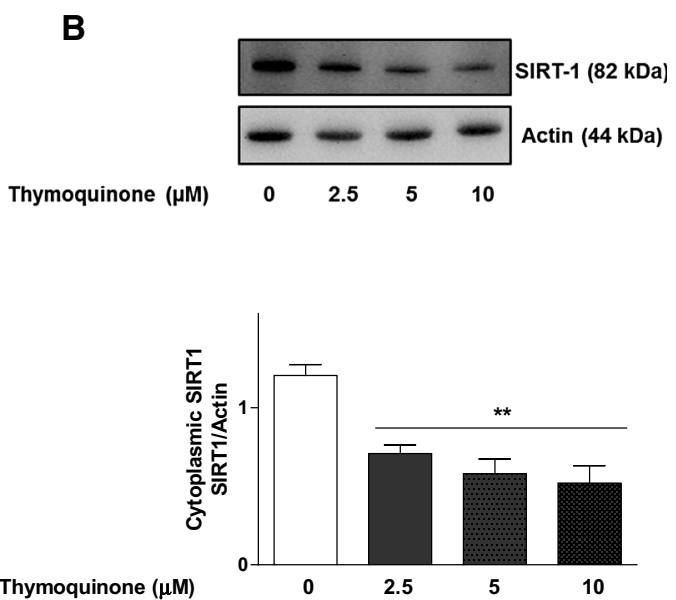

Thymoquinone $(\mu \mathrm{M})$
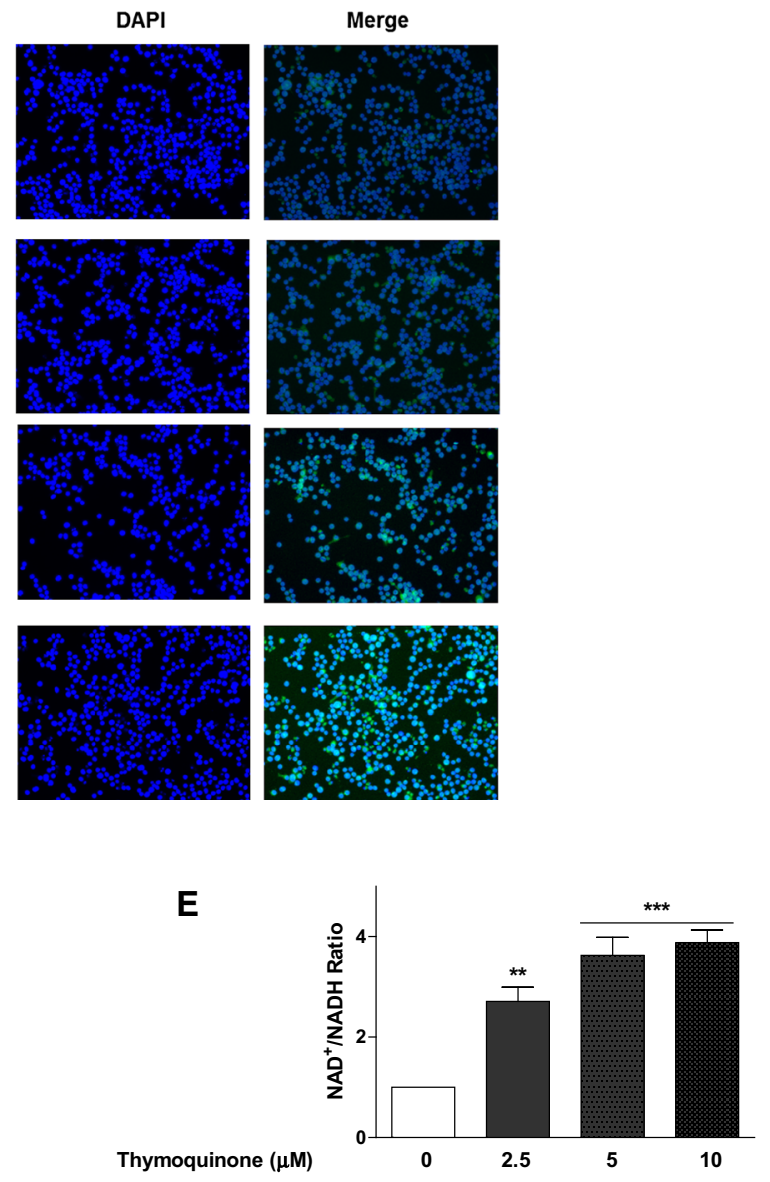

one-way ANOVA with ANOVA post hoc Student Newman-Keuls test). c Immunofluorescence showing nuclear SIRT1 following treatment of BV2 cells with thymoquinone for $12 \mathrm{~h}$. d BV2 cells were treated with vehicle or thymoquinone $(2.5-10 \mu \mathrm{M})$ for $12 \mathrm{~h}$. Nuclear extracts were analysed using mouse ELISA for SIRT1. (Mean $\pm \mathrm{SEM} ; * p<0.001$; one-way ANOVA). e Thymoquinone increases levels of $\mathrm{NAD}^{+}$in $\mathrm{BV} 2$ microglia. (Mean $\pm \mathrm{SEM}$; $* * p<0.01, * * * p<0.001$; one-way ANOVA with ANOVA post hoc Student Newman-Keuls test) 
significant $(p<0.01)$ and concentration-dependent increase in levels of $\mathrm{NAD}^{+}$(Fig. 6e).

\section{Transfection of BV2 microglia with SIRT1 siRNA and treatment with EX527 reversed anti- inflammatory action of thymoquinone}

Following observations suggesting that thymoquinone inhibits acetylation of p65 during neuroinflammation as well as activating SIRT1, we were interested in investigating whether direct activation of SIRT1 contributes to the anti-inflammatory action of the compound. Results in Fig. 7a-e show that anti-inflammatory effects of thymoquinone on the production of TNF $\alpha$, IL-6, IL-1 $\beta$, nitrite and PGE2 were significantly $(p<0.05)$ abolished following transfection of LPS-activated BV2 microglia with

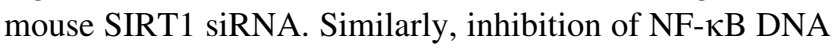
binding by the compound was diminished in the presence of SIRT1 siRNA (Fig. 7f). Interestingly, we observed that the ability of the compound to reduce ROS production following LPS stimulation was unaffected by SIRT1 siRNA transfection (Fig. 7g).

We proceeded to carry out experiments on the role of pharmacological inhibition of SIRT1 on anti-inflammatory effect of thymoquinone by pre-treating BV2 cells with EX527 $(1 \mu \mathrm{M})$ prior to thymoquinone treatment $(10 \mu \mathrm{M})$, and followed by stimulation with LPS. Results in Fig. 8a-f

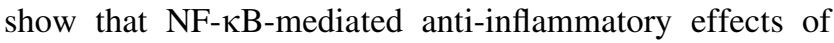
thymoquinone on LPS-induced neuroinflammation were diminished when SIRT1 was inhibited by EX527. However, EX527 treatment did not interfere with antioxidant action of thymoquinone on LPS-induced ROS generation (Fig. 8g).

\section{Thymoquinone activates SIRT1 through AMPK- dependent mechanisms}

Treatment of BV2 microglia with thymoquinone $(10 \mu \mathrm{M})$ resulted in a significant $(p<0.05)$ increase in nuclear accumulation of SIRT1 (Fig. 9a, b). However, this effect was lost when the cells were exposed to compound $\mathrm{C}$ $(10 \mu \mathrm{M})$ prior to treatment with thymoquinone. Similarly, there was increase in $\mathrm{NAD}^{+}$levels produced as a result of thymoquinone treatment was diminished in the presence of compound $\mathrm{C}(10 \mu \mathrm{M})$ (Fig. 9c).

\section{Discussion}

Activation of microglia during neuroinflammation is known to result in the generation of ROS by a process that is facilitated by the NADPH oxidase enzymes [25, 26]. Furthermore, excessive production of ROS through
NADPH oxidase is known to be responsible for neuroinflammation and neurodegeneration [27]. We show that thymoquinone produced a marked reduction in ROS generation induced by LPS stimulation in BV2 microglia, suggesting that the compound is able to attenuate ROS generation in response to neuroinflammation. It is known that activated microglia cells are associated with elevated levels of NADPH oxidase (NOX)-dependent ROS generation [5]. NOX is a multi-subunit enzyme complex which transfers electrons from NADPH to molecular oxygen, forming $\mathrm{O}_{2}{ }^{-}$. Under resting conditions, the different subunits of this complex are localised in the cytosol (p40 phox, $\mathrm{p} 47^{\text {phox }}$ and $\mathrm{p} 67^{\text {phox }}$ ) and in the cell membrane (p22 $2^{\text {phox }}$ and gp91 ${ }^{\text {phox }}$ ). However, following stimulation of the microglia, the complex is assembled in the plasma membrane [27]. Once we established that thymoquinone reduced ROS generation in activated microglia, we then proceeded to show that thymoquinone produced a reduction in elevated levels of $\mathrm{p}$-p $40^{\text {phox }}$ and gp91 ${ }^{\text {phox }}$ proteins in LPS-stimulated microglia, suggesting that an inhibition of these NOX enzymes contribute to the inhibitory effects of the compound on ROS generation during neuroinflammation. Consistent with our findings, thymoquinone was shown in other studies to reduce ROS generation in inflammation [28, 29].

There have been suggestions in the scientific literature linking AMPK activation to inhibition of inflammation [30]. Our results reveal that thymoquinone treatment increased the levels of phosphorylated AMPK $\alpha$ and its upstream kinase LKB1 in the microglia, suggesting that this compound activates the LKB1/AMPK $\alpha$ signalling pathway in the microglia. Thymoquinone has earlier been reported to produce anti-inflammatory effect as well as enhancing the phosphorylation AMPK and LKB1 in a mouse model of fibrosis [31]. In another study reported by Yang et al., the compound activated AMPK in hepatic stellate cells [32]. To our knowledge, this is the first report showing that thymoquinone activates AMPK in the microglia.

Based on reports showing inhibition of neuroinflammation by thymoquinone [20-22], and our observation on the inhibition of cellular ROS generation in LPS-activated microglia, we then asked whether there was a relationship between these activities and AMPK activation by the compound. Interestingly, it was revealed that transfection with AMPK $\alpha$ siRNA as well as pre-treatment with AMPK inhibitor (Compound $\mathrm{C}$ ) resulted in the loss of anti-inflammatory and ROS inhibitory activities of thymoquinone in LPS-activated BV2 microglia. Studies have linked AMPK to inflammation and redox mechanisms. For example, studies reported by Lin et al. [33] and Tsai et al. [7] suggest that lycopene and caffeic acid phenethyl ester (CAPE) produce anti-neuroinflammatory effect through 

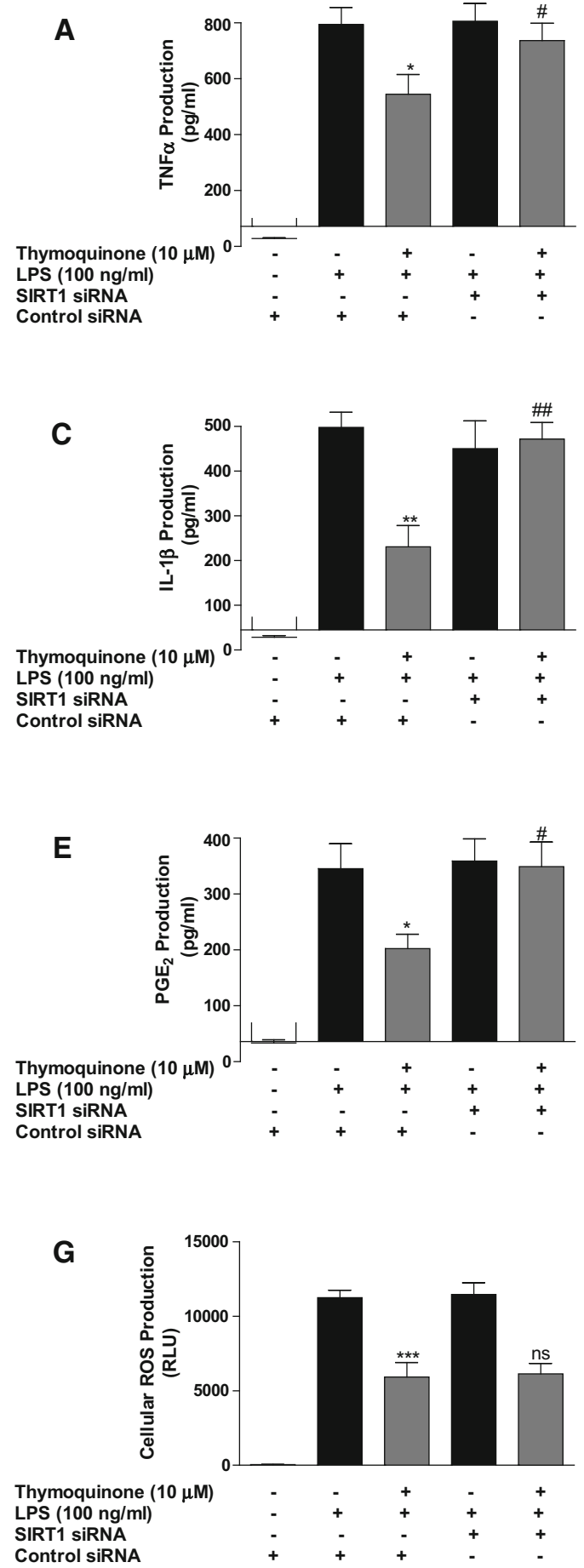

Fig. 7 Inhibition of neuroinflammation by thymoquinone is dependent on SIRT1. Control siRNA- and SIRT1 siRNA-transfected BV2 cells were pre-treated with thymoquinone $(10 \mu \mathrm{M})$ prior to stimulation with LPS $(100 \mathrm{ng} / \mathrm{ml})$ for $24 \mathrm{~h}$. Culture supernatants were analysed for TNF $\alpha(\mathbf{a})$, IL-6 (b), IL-1 $\beta$ (c), nitrite (d) and $\mathrm{PGE}_{2}(\mathbf{e})$. In f nuclear extracts from cells were added to 96 -well plates to which an oligonucleotide containing the NF- $\kappa \mathrm{B}$ consensus site $\left(5^{\prime}-\right.$ GGGACTTTCC- $3^{\prime}$ ) has been immobilised, followed by addition of
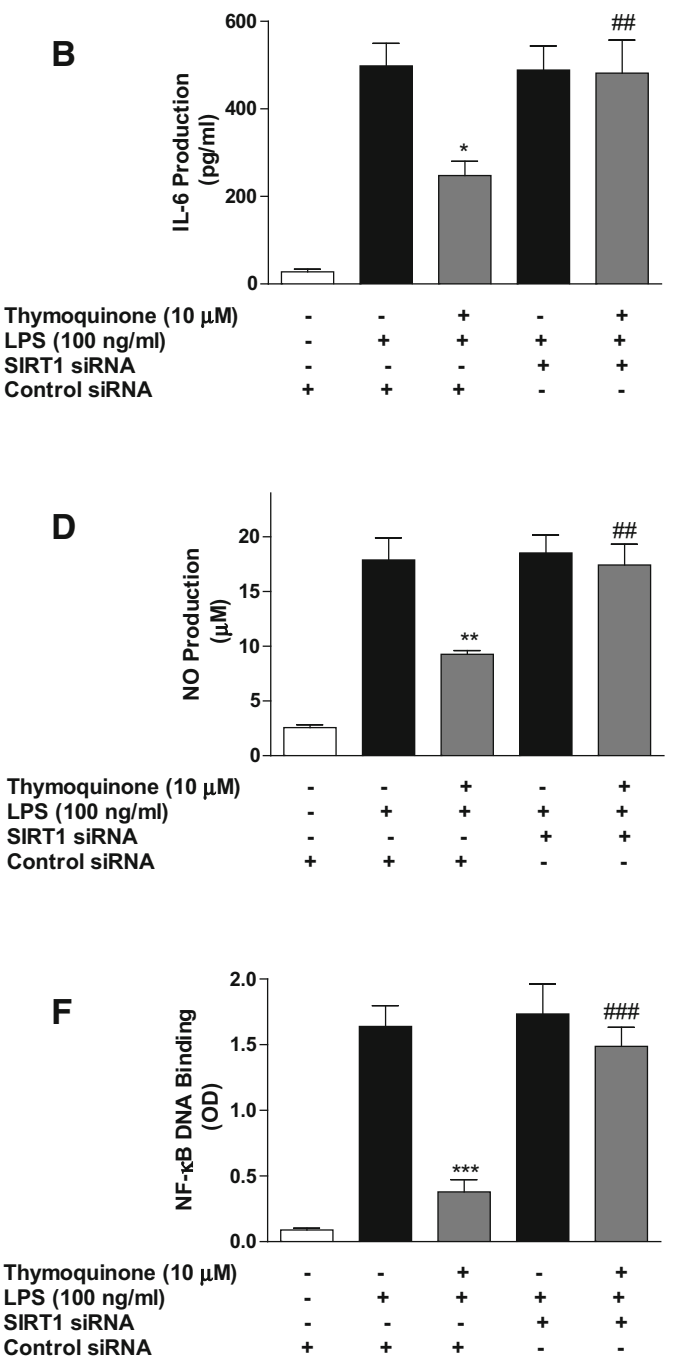

NF- $\kappa \mathrm{B}$ and HRP-conjugated antibodies. Absorbance was read in a microplate reader. Reduction of cellular ROS production in LPSstimulated microglia is not dependent on SIRT1 $(\mathbf{g})$. (Mean \pm SEM; $* * p<0.01, * * * p<0.001$ thymoquinone +LPS treatment compared with LPS (alone) in control siRNA-transfected cells; ${ }^{*} p<0.05$,

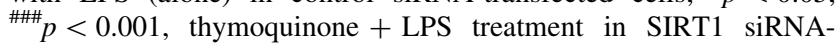
transfected cells compared with thymoquinone + LPS treatment in control siRNA-transfected cells; one-way ANOVA) 

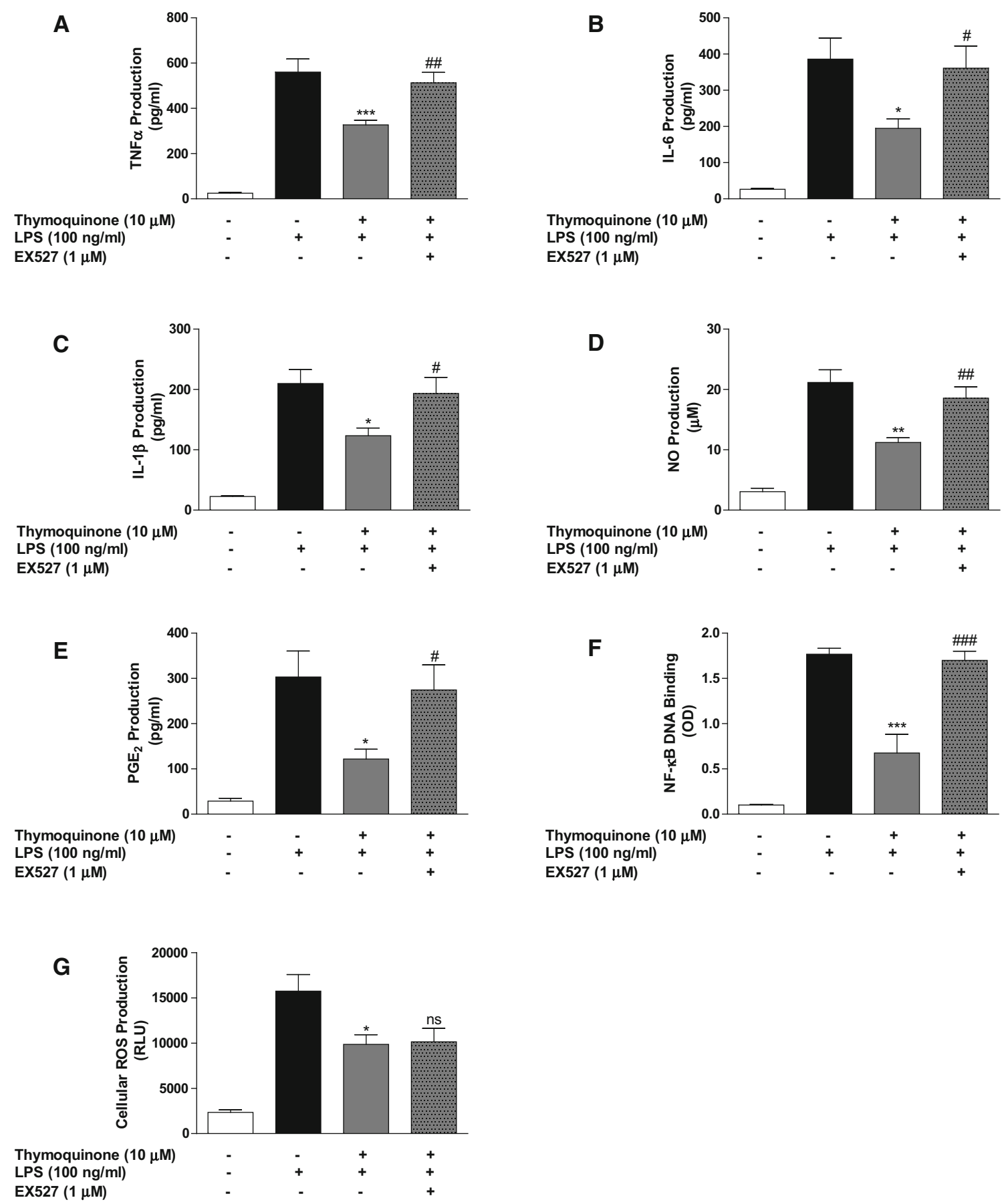

Fig. 8 Inhibition of neuroinflammation by thymoquinone was abolished in the presence of EX527. BV2 cells were treated with EX527 $(1 \mu \mathrm{M})$, followed by thymoquinone $(10 \mu \mathrm{M})$ and LPS $(100 \mathrm{ng} / \mathrm{ml})$ for $24 \mathrm{~h}$. Culture supernatants were collected and analysed for TNF $\alpha(\mathbf{a})$, IL-6 (b), IL-1 $\beta$ (c), nitrite (d) and $\mathrm{PGE}_{2}(\mathbf{e})$. In $\mathbf{f}$ nuclear extracts from cells were added to 96 -well plates to which an oligonucleotide containing the NF- $\kappa \mathrm{B}$ consensus site (5'-GGGACTTTCC-3') has

AMPK $\alpha$-dependent mechanisms. Similar observations have been reported for berberine [34], ginseng [35] and paeonol [36]. We suggest that activation of AMPK possibly contributes to inhibition of neuroinflammation by

been immobilised, followed by addition of NF- $\kappa \mathrm{B}$ and HRPconjugated antibodies. Absorbance was read in a microplate reader. Reduction of cellular ROS production by thymoquinone was not abolished in the presence of EX527 (G). (Mean \pm SEM; $* * p<0.01$, ${ }^{* * *} p<0.001$ compared with LPS stimulation; ${ }^{\#} p<0.05,{ }^{\# \#} p<0.01$, $\#$ \#\# $p<0.001$, EX527 + thymoquinone + LPS treatment compared with thymoquinone + LPS treatment; one-way ANOVA)

thymoquinone, which sheds more light on the mechanisms involved in the activity of this compound.

It has been reported that AMPK activation can promote expression of genes which are involved in antioxidant 
A
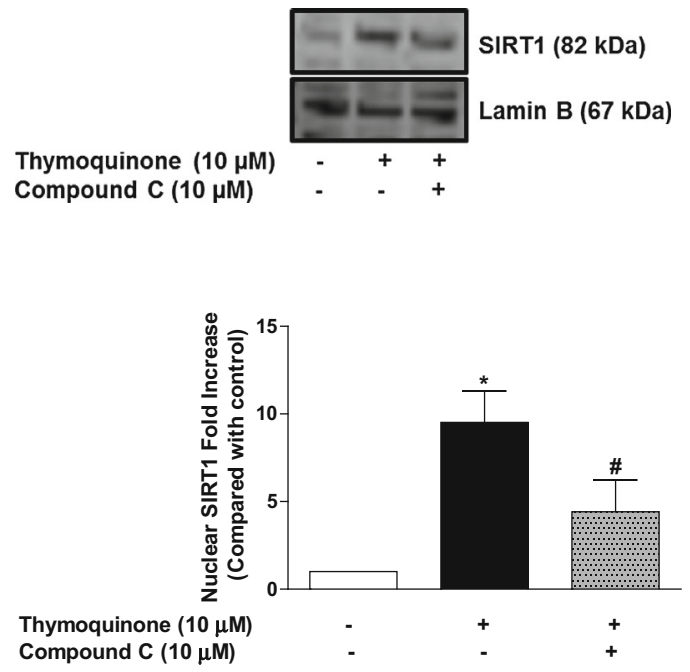

Fig. 9 Activation of $\mathrm{NAD}^{+}$-dependent SIRT1 by thymoquinone was abolished in the presence of compound C. BV2 cells were treated with compound $\mathrm{C}(10 \mu \mathrm{M})$, followed by thymoquinone $(10 \mu \mathrm{M})$ for $24 \mathrm{~h}$. Cell extracts were analysed for nuclear $\operatorname{SIRT1}(\mathbf{a}, \mathbf{b})$ and $\mathrm{NAD}^{+} /$

defence mechanisms [37]. Also, AMPK activation has been shown to increase $\mathrm{NAD}^{+}$levels, resulting in SIRT1 activation and deacetylation-induced activation of targets such as FOXO3a [38]. Interestingly, AMPK activation has been linked to nuclear accumulation of the antioxidant transcription factor Nrf2 [24, 39]. Studies have also shown that upregulation of AMPK abolished the levels of LPS-enhanced NOX-derived ROS in human brain microvascular endothelial cells [40]. Our results showing that inhibition of ROS by thymoquinone is reversed in the presence of AMPK gene knockout and compound $\mathrm{C}$ seem to suggest that activation of AMPK is likely involved reducing LPSinduced ROS generation, and contributes to the antioxidant activity of the compound.

It is now known that inhibition of neuroinflammation could be achieved through processes involved in the deacetylation of $\mathrm{p} 65$. The $\mathrm{NAD}^{+}$-dependent deacetylase SIRT1 is known to deacetylate p65, resulting in the inhibition of the transcriptional ability of NF- $\mathrm{BB}$ [11], and the resulting appearance of pro-inflammatory genes. We therefore became interested in establishing whether this could be linked to a direct effect of the compound on SIRT1. Interestingly, thymoquinone treatment induced significant accumulation of SIRT1 protein in the nucleus of BV2 microglia, while inducing its disappearance from the cytoplasm. The compound also increased the levels of $\mathrm{NAD}^{+}$in the cells, suggesting an NAD-dependent activation of SIRT1. These results suggest that thymoquinone could be blocking LPS-induced p65 acetylation through a
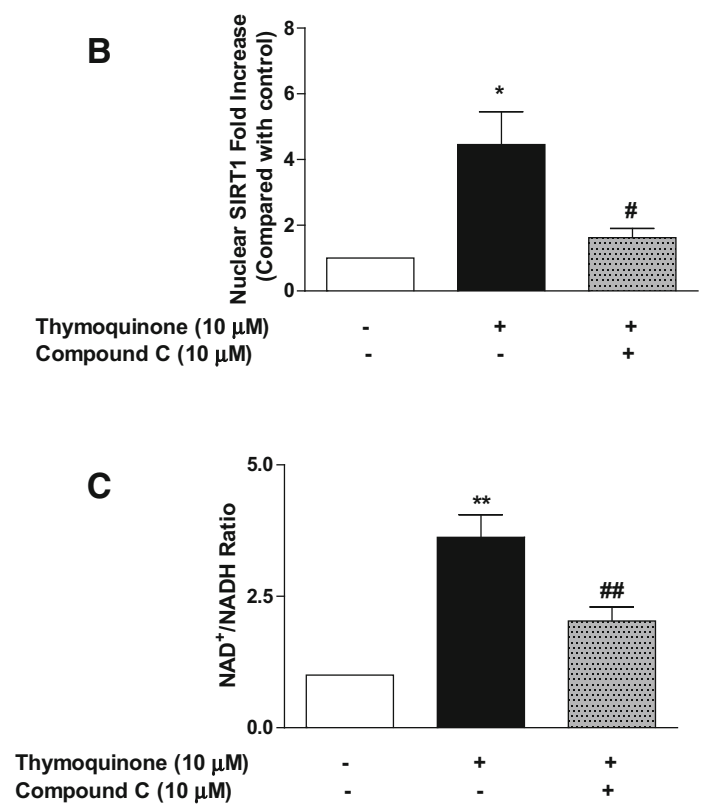

NADH (c). Data and densitometric analyses of three independent experiments are shown (Mean $\pm \mathrm{SEM} ;{ }^{*} p<0.05$, ${ }^{*} p<0.01$; oneway ANOVA)

direct activation of SIRT1, which then deacetylates the protein. The natural SIRT1 activator, resveratrol, has been similarly shown to target NF- $\mathrm{KB}$ activation by promoting deacetylation of RelA/p65 in A $\beta$-stimulated microglia [12]. Resveratrol has also been shown to inhibit inflammatory response through attenuation of LPS-induced production of $\mathrm{NO}, \mathrm{PGE}_{2}$, iNOS, COX-2, TNF $\alpha$, IL-1 $\beta$, as well as inhibition of NF- $\kappa B$ activation in BV2 microglia [41]. We further established that SIRT1 gene knockout and EX527 treatment resulted in the loss of anti-inflammatory but not antioxidant activity of thymoquinone in LPS-activated BV2 microglia. These observations further confirm that thymoquinone activates SIRT1 in the nucleus, resulting in the deacetylation and nuclear export of p65 NF- $\mathrm{kB}$. This results in suppression of transcription of NF- $\mathrm{KB}$-controlled pro-inflammatory genes such as TNF $\alpha$, IL-6, IL- $1 \beta$, as well as COX-2 and iNOS. Our results are similar to those obtained in a study reported by Yang et al., which shows that thymoquinone enhanced SIRT1 protein levels in human hepatic stellate cells [32].

We further showed that $\mathrm{NAD}^{+}$-dependent activation of SIRT1 by thymoquinone requires AMPK. This further suggests a possible interaction between SIRT1 and AMPK in the activity of thymoquinone in BV2 microglia. This interaction may account for the anti-inflammatory activity of the compound in LPS-activated microglia (Fig. 10).

This study has established that thymoquinone inhibits NOX-mediated ROS generation and activates both AMPK and SIRT1 in BV2 microglia. These actions are proposed 


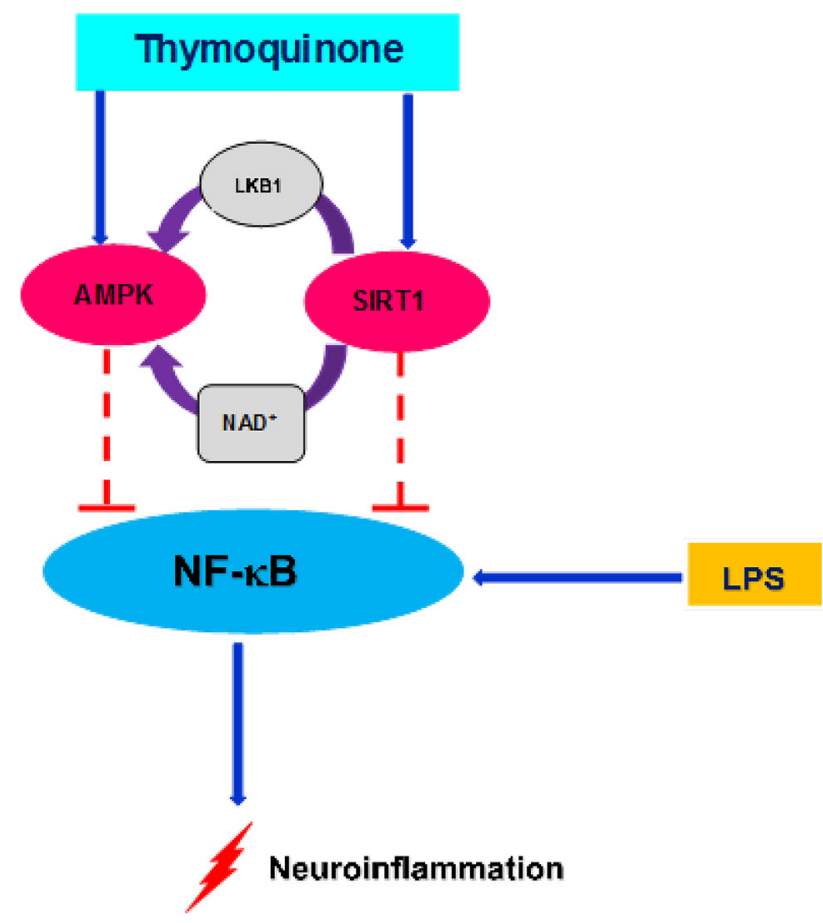

Fig. 10 Inhibition of neuroinflammation by thymoquinone involves activation of AMPK and SIRT1

to contribute to the anti-inflammatory activity of the compound in activated microglia. Further studies are required to determine whether this compound activates SIRT1 in neurons to produce neuroprotective effects.

Acknowledgements This study received financial support from the 2015/2016 round of University Research Fund (International Strategic Partnerships) awarded by the University of Huddersfield to Dr. Olumayokun Olajide.

\section{Compliance with ethical standards}

Conflicts of interest The authors declare that they have no conflict of interest.

Open Access This article is distributed under the terms of the Creative Commons Attribution 4.0 International License (http://crea tivecommons.org/licenses/by/4.0/), which permits unrestricted use, distribution, and reproduction in any medium, provided you give appropriate credit to the original author(s) and the source, provide a link to the Creative Commons license, and indicate if changes were made.

\section{References}

1. Benz CC, Yau C (2008) Ageing, oxidative stress and cancer: paradigms in parallax. Nat Rev Cancer 8:875-879

2. Yang YC, Chou HY, Shen TL, Chang WJ, Tai PH, Li TK (2013) Topoisomerase II-mediated DNA cleavage and mutagenesis activated by nitric oxide underlie the inflammation-associated tumorigenesis. Antioxid Redox Signal 18:1129-1140
3. Chaudhari N, Talwar P, Parimisetty A, Lefebvre d'Hellencourt C, Ravanan P (2014) A molecular web: endoplasmic reticulum stress, inflammation, and oxidative stress. Front Cell Neurosci $8: 213$

4. Rojo A, McBean G, Cindric M, Egea J, López MG, Rada P, Zarkovic N, Cuadrado A (2014) Redox control of microglial function: molecular mechanisms and functional significance. Antioxid Redox Signal 21:1766-1801

5. Qin L, Crews FT (2012) NADPH oxidase and reactive oxygen species contribute to alcohol-induced microglial activation and neurodegeneration. J Neuroinflam 9:5

6. Hardie DG, Ashford ML (2014) AMPK: regulating energy balance at the cellular and whole body levels. Physiology (Bethesda) 29:99-107

7. Tsai CF, Kuo YH, Yeh WL, Wu CY, Lin HY, Lai SW et al (2015) Regulatory effects of caffeic acid phenethyl ester on neuroinflammation in microglial cells. Int $\mathrm{J}$ Mol Sci 16:5572-5589

8. Mounier R, Theret M, Arnold L, Cuvellier S, Bultot L, Goransson O, Sanz N et al (2013) AMPK $\alpha 1$ regulates macrophage skewing at the time of resolution of inflammation during skeletal muscle regeneration. Cell Metab 18:251-264

9. Michan S, Sinclair D (2007) Sirtuins in mammals: insights into their biological function. Biochem J 404:1-13

10. Zhang F, Wang S, Gan L, Vosler PS, Gao Y, Zigmond MJ, Chen J (2011) Protective effects and mechanisms of sirtuins in the nervous system. Prog Neurobiol 95:373-395

11. Yeung F, Hoberg JE, Ramsey CS, Keller MD, Jones DR, Frye RA, Mayo MW (2004) Modulation of NF- $\kappa B-d e p e n d e n t ~ t r a n-$ scription and cell survival by the SIRT1 deacetylase. EMBO J 23:2369-2380

12. Chen J, Zhou Y, Mueller-Steiner S, Chen LF, Kwon H, Yi S, Mucke L, Gan L (2005) SIRT1 protects against microglia-dependent amyloid- $\beta$ toxicity through inhibiting $N F-\kappa B$ signaling. J Biol Chem 280:40364-40374

13. Rajendrasozhan S, Yang SR, Kinnula VL, Rahman I (2008) SIRT1, an antiinflammatory and antiaging protein, is decreased in lungs of patients with chronic obstructive pulmonary disease. Am J Respir Crit Care Med 177:861-870

14. Schug TT, Xu Q, Gao H, Peres-da-Silva A, Draper DW, Fessler MB, Purushotham A, Li X (2010) Myeloid deletion of SIRT1 induces inflammatory signaling in response to environmental stress. Mol Cell Biol 30:4712-4721

15. Chehl N, Chipitsyna G, Gong Q, Yeo CJ, Arafat HA (2009) Antiinflammatory effects of the Nigella sativa seed extract, thymoquinone, in pancreatic cancer cells. HPB (Oxford) 11:373-381

16. Wang D, Qiao J, Zhao X, Chen T, Guan D (2015) Thymoquinone inhibits IL-1 $\beta$-induced inflammation in human osteoarthritis chondrocytes by suppressing NF- $\mathrm{KB}$ and MAPKs signaling pathway. Inflammation 38:2235-2241

17. Kundu JK, Liu L, Shin JW, Surh YJ (2013) Thymoquinone inhibits phorbol ester-induced activation of NF- $\kappa B$ and expression of COX-2, and induces expression of cytoprotective enzymes in mouse skin in vivo. Biochem Biophys Res Commun 438:721-727

18. Umar S, Hedaya O, Singh AK, Ahmed S (2015) Thymoquinone inhibits TNF- $\alpha$-induced inflammation and cell adhesion in rheumatoid arthritis synovial fibroblasts by ASK1 regulation. Toxicol Appl Pharmacol 287:299-305

19. Alemi M, Sabouni F, Sanjarian F, Haghbeen K, Ansari S (2013) Anti-inflammatory effect of seeds and callus of Nigella sativa $\mathrm{L}$. extracts on mix glial cells with regard to their thymoquinone content. AAPS PharmSciTech 14:160-167

20. Taka E, Mazzio EA, Goodman CB, Redmon N, Flores-Rozas H, Reams R, Darling-Reed S, Soliman KF (2015) Anti-inflammatory 
effects of thymoquinone in activated BV-2 microglial cells. J Neuroimmunol 286:5-12

21. Wang Y, Gao H, Zhang W, Zhang W, Fang L (2015) Thymoquinone inhibits lipopolysaccharide-induced inflammatory mediators in BV2 microglial cells. Int Immunopharmacol 26:169-173

22. Velagapudi R, Kumar A, Bhatia HS, El-Bakoush A, Lepiarz I, Fiebich BL, Olajide OA (2017) Inhibition of neuroinflammation by thymoquinone requires activation of Nrf2/ARE signalling. Int Immunopharmacol 48:17-29

23. Lee J, Kim S (2014) Upregulation of heme oxygenase-1 expression by dehydrodiconiferyl alcohol (DHCA) through the AMPK-Nrf2 dependent pathway. Toxicol Appl Pharmacol 281:87-100

24. Zimmermann $\mathrm{K}$, Baldinger J, Mayerhofer B, Atanasov AG, Dirsch VM, Heiss EH (2015) Activated AMPK boosts the Nrf2/ HO-1 signaling axis - a role for the unfolded protein response. Free Radic Biol Med 88:417-426

25. Infanger DW, Sharma RV, Davisson RL (2006) NADPH oxidases of the brain: distribution, regulation, and function. Antioxid Redox Signal 8:1583-1596

26. Dohi K, Ohtaki H, Nakamachi T, Yofu S, Satoh K, Miyamoto K, Song D, Tsunawaki S, Shioda S, Aruga T (2010) Gp91phox (NOX2) in classically activated microglia exacerbates traumatic brain injury. J Neuroinflam 7:41

27. Hsieh HL, Yang CM (2013) Role of redox signaling in neuroinflammation and neurodegenerative diseases. Biomed Res Int 2013:484613

28. Thummuri D, Jeengar MK, Shrivastava S, Nemani H, Ramavat RN, Chaudhari P, Naidu VG (2015) Thymoquinone prevents RANKL-induced osteoclastogenesis activation and osteolysis in an in vivo model of inflammation by suppressing NF- $\mathrm{KB}$ and MAPK Signalling. Pharmacol Res 99:63-73

29. Boudiaf K, Hurtado-Nedelec M, Belambri SA, Marie JC, Derradji Y, Benboubetra M, El-Benna J, Dang PM (2016) Thymoquinone strongly inhibits fMLF-induced neutrophil functions and exhibits anti-inflammatory properties in vivo. Biochem Pharmacol 104:62-73

30. Galic S, Fullerton MD, Schertzer JD, Sikkema S, Marcinko K, Walkley CR, Izon D, Honeyman J, Chen ZP, van Denderen BJ, Kemp BE, Steinberg GR (2011) Hematopoietic AMPK $\beta 1$ reduces mouse adipose tissue macrophage inflammation and insulin resistance in obesity. J Clin Invest 121:4903-4915

31. Bai T, Yang Y, Wu YL, Jiang S, Lee JJ, Lian LH, Nan JX (2014) Thymoquinone alleviates thioacetamide-induced hepatic fibrosis and inflammation by activating LKB1-AMPK signaling pathway in mice. Int Immunopharmacol 19:351-357

32. Yang Y, Bai T, Yao YL, Zhang DQ, Wu YL, Lian LH, Nan JX (2016) Upregulation of SIRT1-AMPK by thymoquinone in hepatic stellate cells ameliorates liver injury. Toxicol Lett 262:80-91

33. Lin HY, Huang BR, Yeh WL, Lee CH, Huang SS, Lai CH, Lin H, Lu DY (2014) Antineuroinflammatory effects of lycopene via activation of adenosine monophosphate-activated protein kinase$\alpha 1 /$ heme oxygenase-1 pathways. Neurobiol Aging 35:191-202

34. Lu DY, Tang CH, Chen YH, Wei IH (2010) Berberine suppresses neuroinflammatory responses through AMP-activated protein kinase activation in BV-2 microglia. Cell Biochem 110:697-705

35. Lee YY, Park JS, Lee EJ, Lee SY, Kim DH, Kang JL, Kim HS (2015) Anti-inflammatory mechanism of ginseng saponin metabolite Rh3 in lipopolysaccharide-stimulated microglia: critical role of $5^{\prime}$-adenosine monophosphate-activated protein kinase signaling pathway. J Agric Food Chem 63:3472-3480

36. Lin C, Lin HY, Chen JH, Tseng WP, Ko PY, Liu YS, Yeh WL, Lu DY (2015) Effects of paeonol on anti-neuroinflammatory responses in microglial cells. Int J Mol Sci 16:8844-8860

37. Essick EE, Sam F (2010) Oxidative stress and autophagy in cardiac disease, neurological disorders, aging and cancer. Oxid Med Cell Longev 3(168): 177

38. Wu SB, Wu YT, Wu TP, Wei YH (2014) Role of AMPK-mediated adaptive responses in human cells with mitochondrial dysfunction to oxidative stress. Biochim Biophys Acta 1840:1331-1344

39. Joo MS, Kim WD, Lee KY, Kim JH, Koo JH, Kim SG (2016) AMPK facilitates nuclear accumulation of Nrf2 by phosphorylating at serine 550. Mol Cell Biol 36:1931-1942

40. Hu M, Liu B (2016) Resveratrol attenuates lipopolysaccharideinduced dysfunction of blood-brain barrier in endothelial cells via AMPK activation. Korean J Physiol Pharmacol 20:325-332

41. Zhong LM, Zong Y, Sun L, Guo JZ, Zhang W, He Y, Song R, Wang WM, Xiao CJ, Lu D (2012) Resveratrol inhibits inflammatory responses via the mammalian target of rapamycin signaling pathway in cultured LPS-stimulated microglial cells. PLoS ONE 7:e32195 